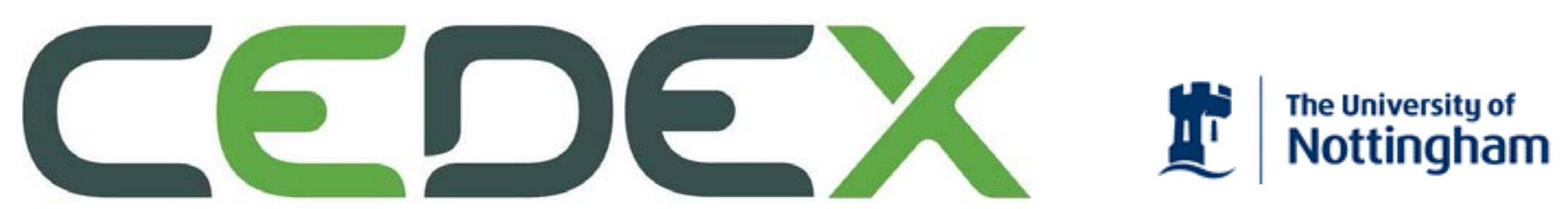

CENTRE FOR DECISION RESEARCH \& EXPERIMENTAL ECONOMICS

Discussion Paper No. 2009-19

Simon Gächter, Daniele Nosenzo, Elke Renner and Martin Sefton October 2009
Who Makes a Good Leader?

Cooperativeness, Optimism and Leading-by-Example 

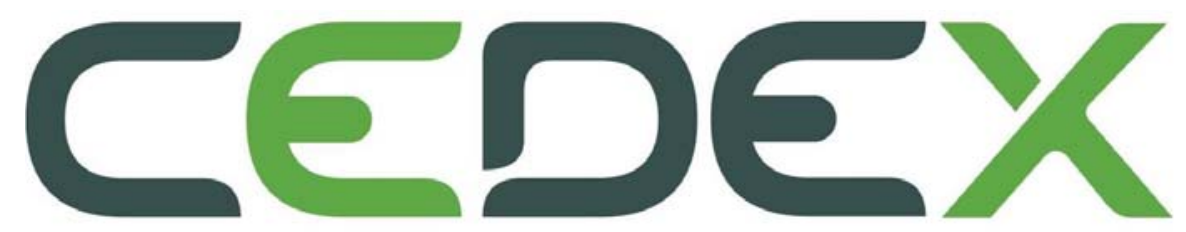

CENTRE FOR DECISION RESEARCH \& EXPERIMENTAL ECONOMICS

The Centre for Decision Research and Experimental Economics was founded in 2000, and is based in the School of Economics at the University of Nottingham.

The focus for the Centre is research into individual and strategic decision-making using a combination of theoretical and experimental methods. On the theory side, members of the Centre investigate individual choice under uncertainty, cooperative and non-cooperative game theory, as well as theories of psychology, bounded rationality and evolutionary game theory. Members of the Centre have applied experimental methods in the fields of Public Economics, Individual Choice under Risk and Uncertainty, Strategic Interaction, and the performance of auctions, Markets and other economic institutions. Much of the Centre's research involves collaborative projects with researchers from other departments in the UK and overseas.

Please visit http://www.nottingham.ac.uk/economics/cedex/ for more information about the Centre or contact

Karina Terry

Centre for Decision Research and Experimental Economics

School of Economics

University of Nottingham

University Park

Nottingham

NG7 2RD

Tel: +44 (0) 1159515620

Fax: +44 (0) 1159514159

karina.terry@nottingham.ac.uk

The full list of CeDEx Discussion Papers is available at http://www.nottingham.ac.uk/economics/cedex/papers/index.html 


\title{
WHO MAKES A GOOD LEADER? \\ COOPERATIVENESS, OPTIMISM AND LEADING-BY-EXAMPLE
}

\author{
SIMON GÄCHTER, DANIELE NOSENZO, ELKE RENNER and MARTIN SEFTON*
}

6 October 2009

[Forthcoming, Economic Inquiry]

We examine the characteristics of effective leaders in a simple leader-follower voluntary contributions game. We focus on two factors: the individual's cooperativeness and the individual's beliefs about the cooperativeness of others. We find that groups perform best when led by those who are cooperatively inclined. Partly this reflects a false consensus effect: cooperative leaders are more optimistic than non-cooperators about the cooperativeness of followers. However, cooperative leaders contribute more than non-cooperative leaders even after controlling for optimism. We conclude that differing leader contributions by differing types of leader in large part reflects social motivations. (JEL A13, C92, D03)

\footnotetext{
* This work was funded by the British Academy under small research grant SG-44918. We gratefully acknowledge helpful comments by anonymous referees and Yan Chen. All authors are at the Centre for Decision Research and Experimental Economics (CeDEx), University of Nottingham, School of Economics, Sir Clive Granger Building, University Park, Nottingham NG7 2RD, United Kingdom.
} 
"Then I would look for integrity. A leader sets an example, especially a strong leader. He or she is someone on whom people ... in the organization model themselves." Peter Drucker on Picking a Leader, excerpted from "The Daily Drucker" (p. 5, Drucker (2004)).

\section{INTRODUCTION}

One of the challenges facing leaders is how to get followers to do something they otherwise would not do. In settings where followers are tempted to free-ride on the contributions of others, the challenge is for leaders to somehow induce followers to eschew their narrowly-defined personal interests in order to promote the wider interests of the group. Such settings are commonplace in the workplace, and also in political and military organizations. One mechanism by which a leader may influence her followers is through leading-by-example. Recent experimental research has shown that followers respond strongly to the example set by a leader (Gächter and Renner (2003); Gächter and Renner (2007), Moxnes and van der Heijden (2003); Arbak and Villeval (2007); Güth, et al. (2007); Levati, Sutter and van der Heijden (2007); Potters, Sefton and Vesterlund (2007); Kumru and Vesterlund (2008); Rivas and Sutter (2008); Pogrebna, et al. (2009)).

In this paper we report an experiment on a simple leader-follower game in which efficiency and self-interested behavior are in conflict. More specifically, we study a sequential voluntary contributions game where each player has an endowment and can choose how much of this to contribute to a project. Joint earnings are maximized when each player contributes their full endowment, but if subjects maximize own-earnings they will contribute nothing. We focus on the question of who makes the best leader, in terms of promoting efficient outcomes. We focus on two factors: the individual's cooperativeness, as measured by her willingness to contribute to the project when others do so, and the individual's beliefs about the cooperativeness of others. ${ }^{1}$

\footnotetext{
${ }^{1}$ Of course there are many other aspects of leadership that we do not address in this paper. See Yukl (1989) for a comprehensive treatment. In natural settings the role of a leader may encompass a broad range of activities coordinating and organizing efficient allocation of individual tasks, mediating conflicts, designing incentive schemes, disciplining deviators, maintaining group relations, etc. - and these activities may require different (psychological) qualities. See Van Vugt and De Cremer (2002) for a social psychological perspective on aspects of leadership in social dilemma situations.
} 
Previous experiments with this type of game show that subjects do make positive contributions, but, at the same time, contributions fall short of efficient levels. Moreover, there is substantial heterogeneity in decisions across subjects in both roles. Among followers, some maximize own earnings but others contribute substantial amounts. Moreover, follower contributions are heavily influenced by leader contributions. In experiments with sequential prisoner's dilemmas second movers often cooperate if the first mover cooperates, but hardly ever if the first mover defects (Clark and Sefton (2001)), and in experiments with sequential contributions to a public good followers' contributions tend to increase with leader contributions (Gächter and Renner (2003); Gächter and Renner (2007)). Thus, cooperative behavior by followers is often described as evidence of reciprocation or conditional cooperation (Keser and van Winden (2000); Fischbacher, Gächter and Fehr (2001); Frey and Meier (2004); Croson (2007); Glöckner, et al. (forthcoming)).

The experiments also reveal variability in leader decisions. Some leaders contribute nothing, almost certainly leading the group toward the lowest possible joint earnings. Other leaders contribute large amounts. If matched with a conditional cooperator this leads to high joint earnings, but there is also the possibility of being suckered when matched with a self-interested player. Compared with follower decisions, it is more difficult to interpret leader decisions. If a person contributes a lot in the role of leader is it because they are somehow cooperatively inclined, or simply because they are self-interested but optimistic about the prospects of meeting a cooperator? If a person contributes nothing is it because they are selfish, or are they cooperators who are pessimistic about the prospects of meeting another cooperator? And, what type of player is likely to set a better example as a leader?

To answer these questions we present a new experiment based on a leader-follower game in which contribution decisions were elicited using the strategy method and subjects played in both roles. Using decisions in the role of follower we are able to classify players according to their degree of conditional cooperativeness. Correlating these measures with their own decisions in the role of leader allows a within-subject cross-tabulation of leader contribution against follower type. Thus we are able to answer whether cooperators make better or worse leaders. In order to answer whether differences between leader decisions reflect differing underlying social motivations or differing expectations about the follower we also have subjects predict what their opponent will do in the role of a follower. These predictions are used to gauge how optimistic 
subjects are about the chances of meeting a cooperator, and we then ask whether leadership decisions vary across follower types controlling for this degree of optimism. That is, we ask whether optimistic cooperators or optimistic self-interested non-cooperators make better leaders.

From their follower decisions we classify about half of our subjects as non-cooperative and about half as cooperative to some degree. In the role as leader we find that cooperators contribute substantially more than non-cooperators. Although several variables help predict leader decisions - for example economists contribute less than non-economists - the most useful variable for explaining leader contributions is their degree of (conditional) cooperativeness. We find that part (roughly, a quarter) of the difference between the leader contributions of "Non-Cooperators" and "Strong Cooperators" can be attributed to their differing beliefs. These differences in beliefs are consistent with a false consensus effect (Ross, Greene and House (1977)). Non-Cooperators tend to expect they will be paired with another Non-Cooperator and thus contribute little, whereas Strong Cooperators are more optimistic about the prospect of being paired with another Strong Cooperator and so contribute more. Even so, after controlling for optimistic beliefs Strong Cooperator leaders still contribute substantially more than Non-Cooperator leaders. Thus, we conclude that differing leader contributions by differing types of leader must in large part reflect social motivations. Groups perform best when led by those who are cooperatively inclined.

Our study is related to a number of experimental papers that explore how social preferences affect play in social dilemmas by examining the correlations between decisions in the role of first-mover, decisions in the role of second mover, and beliefs about opponents, in games where subjects play both roles (Fischbacher, et al. (2001); Vyrastekova and Garikipati (2005); Chaudhuri and Gangadharan (2007); Blanco, Engelmann and Normann (2008); Altmann, Dohmen and Wibral (2008); Blanco, et al. (2009); Bruttel and Eisenkopf (2009)). We discuss this related literature in the conclusions.

The remainder of the paper is organized as follows. In the next Section we describe our experimental design and procedures. Section 3 presents our results. We offer concluding comments in Section 4. 


\section{DESIGN AND PROCEDURES}

\section{A. The Experimental Game}

Our experiment is based on a simple two-player leader-follower game. Each player is endowed with 5 tokens, and must decide how many to contribute to a joint project. Leaders move first and their contribution decision is revealed to the Follower before the Follower chooses her own contribution. After the Follower's choice, the game ends and players' earnings are determined. For each token contributed to the project both players receive $£ 1$, and for each token not contributed to the project that player receives $£ 1.50$. Thus, player $i$ 's earnings are given by

$$
\pi_{i}=1.5 \times\left(5-c_{i}\right)+c_{i}+c_{j}
$$

where $c_{i}, c_{j} \in\{0,1,2,3,4,5\}$ represent the contribution decisions of player $i$ and $j$, for $i, j \in$ $\{$ Leader, Follower $\}$ and $i \neq j$.

In our experiment we implemented a one-shot version of this game and had subjects make decisions both in the role of Leader and Follower. Follower's decisions were elicited using the strategy method (Selten (1967)), i.e. they had to specify complete strategies in the game-theoretic sense. Thus, participants in our experiments were asked to make in total seven contribution decisions: one contribution decision in the role of Leader and six contribution decisions in the role of Follower, one for each possible contribution by the Leader. Only after all decisions had been made were subjects assigned a role in the experiment and paid according to the decisions they made in that role: with probability one half they were assigned the role of Leader and with probability one half the role of Follower. Hence, all seven contribution decisions were elicited using monetary incentives.

Subjects also had to complete a "Prediction Task". In this task subjects were asked to predict the contribution decisions that the other person in their group had made in the role of Follower. Thus subjects made six point predictions, one for each contribution decision their opponent made in the role of Follower. Subjects earned $£ 0.50$ for each correct prediction.

Immediately after having submitted their decisions, subjects were asked to complete a short post-experimental questionnaire asking for basic demographic and attitudinal information. This included a self-assessment of subjects' risk attitudes, which were elicited using the question suggested by Dohmen, et al. (forthcoming). The question reads: "Are you generally a person 
who is fully prepared to take risks or do you try to avoid taking risks?", and subjects answered on a scale from 1 (unwilling to take risks) to 10 (fully prepared to take risk). ${ }^{2}$ To measure and control for inherent predisposition to self-interested behavior we also employed the "Machiavellian instrument" (Christie and Geis (1970)), a psychometric test consisting of 20 statements - such as "anyone who completely trusts anyone else is asking for trouble" or "it is hard to get ahead without cutting corners here and there" - to which subjects were asked to agree or disagree using a 7-level Likert scale. Those who tend to agree with the statements score higher on the Machiavellian instrument, signaling a combination of selfishness, cynicism about human nature and manipulativeness. ${ }^{3}$

\section{B. Discussion of the Design}

Our main interest lies in exploring the relation between subjects' Leader contributions, their own cooperation preferences and their expectations about others' cooperation preferences. We measure subjects' cooperation preferences by the extent to which they are conditionally cooperative in their Follower contribution response to the Leader's contribution decisions. Note that the Follower's decision directly determines the distribution of earnings and thus provides a cleaner measure of cooperation preferences than the Leader's decision. It is possible that a Leader may contribute not because they are inherently cooperative, but rather because they expect a cooperative response that makes contributing pay. In order to measure a Follower's degree of conditional cooperation we need to observe a follower response to different possible leader contribution decisions. ${ }^{4}$ The use of the strategy method allows us to observe subjects' follower contribution responses conditional on each possible Leader contribution decision without either resorting to repeated play (which might induce strategic confounds) or using

\footnotetext{
${ }^{2}$ The average response was 6.05 (s.d. 2.10).

${ }^{3}$ Higher Machiavellian scores are generally associated with less generous offers in dictator games, but not in ultimatum games (see, e.g. Carpenter, Burks and Verhoogen (2005); Carpenter, Verhoogen and Burks (2005); Spitzer, et al. (2007)). Meyer (1992) shows that subjects scoring high on the Machiavellian instrument are less likely to reject unfair offers in a one-shot ultimatum game with hypothetical payoffs. Burks, Carpenter and Verhoogen (2003) find that subjects with higher Machiavellian scores send less in trust games, while Gunnthorsdottir, McCabe and Smith (2002) find that subjects with higher Machiavellian scores are less likely to reciprocate trust.

${ }^{4}$ For example, observing a Follower that contributes zero tokens in response to a leader contribution of zero tokens does not reveal whether the subject is a conditional cooperator (and hence responds with low contributions to low leader contributions) or whether he or she is motivated by own-profit maximization. What we need to observe is the Follower's contributions in different subgames.
} 
deception. Thus, from each subject we elicit in an incentive compatible way a complete vector of conditional contribution decisions that we then use to classify subjects into "cooperation types" according to their revealed (conditional) cooperativeness.

Letting subjects play in both roles of the game allows us to correlate subjects' cooperativeness (measured, as explained, by their conditional contribution decisions) with their (unconditional) contribution decision in the role of Leader. Thus, we can observe a withinsubject cross-tabulation of Leader contribution against Follower cooperation types that allows us to explore whether more cooperative types make better or worse Leaders.

Since we are also interested in how subjects' beliefs about others' cooperation preferences relate to their leader contributions and their cooperation types, we also have subjects predict what their opponent will do in the role of Follower. That is, from each subject we elicit a vector of predicted conditional contribution decisions. This allows us to measure how optimistic subjects are about the cooperativeness of the players they are matched with. Subjects were given monetary incentives for correctly predicting others' contributions and could earn up to $£ 3$ from the prediction task. Note that this gives subjects an incentive to predict the most likely response to each possible leader contribution, rather than report their subjective probability distributions over possible responses. In order to elicit subjective probability distributions over possible responses in an incentive compatible manner subjects would have had to complete a 6x6 matrix, and we would have had to use a different scoring rule. This of course would only be incentivecompatible to the extent that subjects understand the mechanism. Our simpler Prediction Task has the advantage that it yields an operational measure of optimism while keeping the task manageable for subjects.

Decisions in the role of Leader and Follower and beliefs were elicited using a single computer screen so that subjects could make and revise their choices in any order they liked. ${ }^{5}$ This design choice was motivated by a desire to avoid potential ordering effects which could have arisen had we prompted subjects to complete the three experimental tasks in a predetermined order.

\footnotetext{
${ }^{5}$ A screenshot of the computer screen used to elicit subjects' decisions and beliefs was included in the instructions that were given to subjects, which are reproduced in the Appendix.
} 


\section{Experimental Procedures}

The experiment was conducted at the University of Nottingham in Autumn 2008 using subjects recruited from a university-wide pool of students who had previously indicated their willingness to be paid volunteers in decision-making experiments. ${ }^{6}$ Six sessions were conducted, four with 18 participants, one with 16 participants and one with 14 participants: thus, 102 subjects participated in total. The average age was 19.7 years and $55 \%$ were male. No subject took part in more than one session.

All sessions used an identical protocol. Upon arrival, subjects were welcomed and randomly seated at visually separated computer terminals. Subjects were then given a written set of instructions that the experimenter read aloud. The instructions included a set of control questions about how choices translated into earnings. Subjects had to answer all the questions correctly before the experiment could continue. The instructions also included a screenshot of the screen on which subjects entered their decisions. The instructions did not use the labels "Leader" and "Follower", but rather referred to "First Movers" and "Second Movers".

The decision-making phase of the session consisted of three tasks: two decision tasks and the prediction task. In the two decision tasks subjects were asked to make contribution decisions both in the role of Leader and in the role of Follower. Subjects were informed at the beginning of the experiment that they would have had to make contribution decisions in both roles and that only after all decisions had been made would they have been informed of their actual role. All decisions were made anonymously, and neither during nor after the experiment were subjects informed about the identity of the other person in their group. Once everyone in the room had completed the three tasks subjects were informed of their role. Decisions and predictions were then implemented and subjects paid accordingly.

With our design players’ earnings can range from a maximum of $£ 15.50$ ( $£ 12.50$ if a player contributes 0 tokens to the joint project while her opponent contributes 5 tokens, plus $£ 3$ if she reports 6 correct predictions) to a minimum of $£ 5$. In the experiment, subjects' earnings ranged from $£ 6.00$ to $£ 15.00$, averaging $£ 9.39$ (at the time of the experiment $£ 1 \approx \$ 1.50$ ). On average the experimental sessions lasted about 50 minutes, including the completion of a post-experimental questionnaire and the payments.

\footnotetext{
${ }^{6}$ Subjects were recruited through the online recruitment system ORSEE (Greiner (2004)). The experiment was programmed and conducted with the software z-Tree (Fischbacher (2007)).
} 


\section{DATA ANALYSIS}

The following analysis of data is structured around our main research questions: What type of player makes the best Leader? And, do different Leader contributions reflect differing underlying social motivations, or differing expectations about the Follower? To explore these questions:

i. We first classify subjects' cooperativeness according to the degree of conditional cooperativeness exhibited by their contribution responses in the role of Follower.

ii. We then explore the relation between subjects' cooperativeness and their (unconditional) contribution decisions in the role of Leader. Thus we will be able to answer whether more cooperative types make better or worse Leaders.

iii. In a third step, we ask whether cooperativeness is systematically related to beliefs about the cooperativeness of others and whether differences in beliefs are related to differences in Leaders' unconditional contribution decisions.

\section{A. Expressed Cooperation Preferences and Cooperation Types}

We measure subjects' cooperativeness using their conditional contribution decisions in the role of Follower. Subjects are classified as Non-Cooperators (NC) if they contribute nothing in the role of Follower irrespective of the Leader's contribution. Forty-six percent of our 102 subjects fall into the NC category. The remaining subjects are classified into three different cooperation types according to the following criterion. For each subject we computed how a (hypothetical) self-interested Leader would best-respond to the vector of conditional contribution decisions submitted by this subject. ${ }^{7}$ If even a self-interested Leader would contribute her entire endowment as a best-response to the subject's vector of conditional contributions, we conclude that the subject must exhibit a strong degree of conditional cooperativeness. We classify such a subject as a Strong Cooperator (SC). Twenty-six percent of our subjects fall into this category. A subject is classified as a Weak Cooperator (WC) if, when matched with her, a self-interested Leader would find it optimal to contribute some, but not all, of her tokens. Twenty-two percent of the subjects can be classified as WC. Finally, if a subject submitted a vector of contributions that contains positive contributions in response to some of the Leader's contributions, but does

\footnotetext{
${ }^{7}$ Should the Leader be indifferent between two or more contribution decisions, the largest contribution is used for computing the Leader's best-response.
} 
not give an incentive to a self-interested Leader to contribute any token to the project, we classify the subject in the category Other. Only six percent of subjects fall into this category. ${ }^{8}$

Figure 1 depicts - both separately for each preference type and aggregated across types the average contribution decisions subjects made in the role of Follower as a function of the contribution level by the Leader. ${ }^{9}$

FIGURE 1

Average Follower Contribution

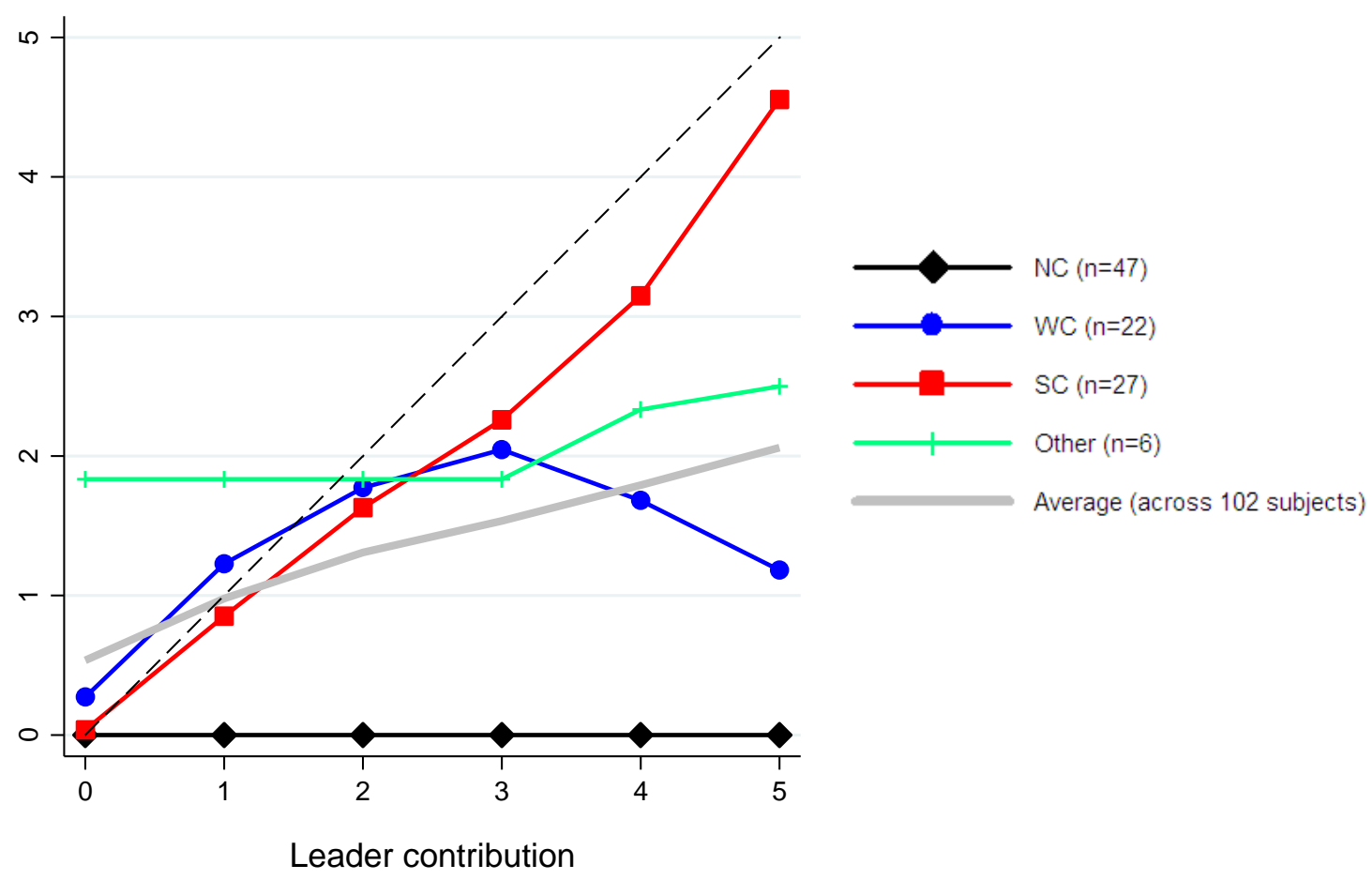

\section{B. Which Cooperation Type Makes a Better Leader?}

We next move to the analysis of the relation between subjects' cooperativeness and their contribution decisions as Leaders. Figure 2 plots the average Leader contribution decisions

\footnotetext{
${ }^{8}$ Half of these subjects are "unconditional co-operators" who contribute the same (non-zero) amount irrespective of the Leader's contribution. The other half contributes 1 or 2 tokens only if the Leader contributes 4 or 5 tokens.

${ }^{9}$ Note that the patterns of contribution decisions of NC, SC, WC and Other closely resemble the average contribution patterns typically found in linear public goods games for "Free Rider", "Conditional Cooperator", "Hump-shaped" and "Other" according to the classification system introduced by Fischbacher, et al. (2001). In fact the two classification systems are highly consistent with one another: all NC and Other would be classified as Free Riders and Other respectively, 85\% of SC subjects as Conditional Cooperators, and 64\% of WC subjects as Humpshaped Contributors.
} 
separately for the three major preference types. ${ }^{10} \mathrm{SC}$ Leaders are those who contribute most to the public good (about 2.8 tokens on average), while NC Leaders contribute on average least (slightly more than 0.5 tokens on average). WC Leaders' contribution decisions fall midway between the contributions of NC and SC Leaders.

We can strongly reject the hypothesis that types contribute similar amounts (KruskalWallis test: $\left.\chi^{2}(2 d . f)=38.65,. p<0.001\right)$. Pair-wise two-sided Mann-Whitney-U-tests reveal that Non-Cooperator Leader contributions differ significantly from Weak Cooperator Leader contributions $(z=4.575, p<0.001)$, which in turn differ significantly from Strong Cooperator Leader contributions $(z=2.065, p=0.039)$.

FIGURE 2.

Average Contribution in the Role of Leader*

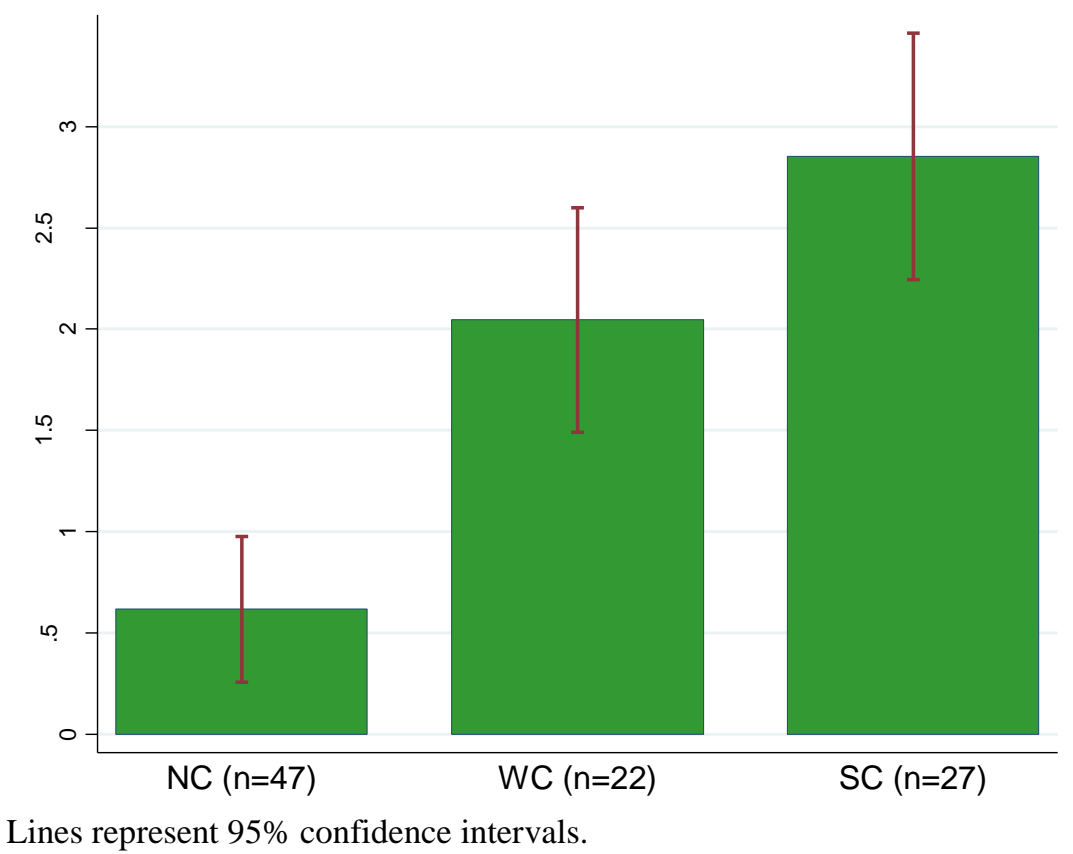

Regression analysis of Leaders' contributions on a set of dummy variables identifying the three Leader types shows that the results are substantially robust to a set of controls for

\footnotetext{
${ }^{10}$ In the remainder of the paper we will focus our analysis on the three major groups and ignore the subjects we classified as Other. With only six subjects in the Other category we would not be able to draw any valid inference from their behavior and their inclusion in the analysis would only unnecessarily complicate the exposition of our results. All our findings are robust to whether we include or exclude these six subjects.
} 
individual and session effects (Table 1). ${ }^{11}$ Models I to III build incrementally including personal characteristics (Models II and III) and controls for session effects (Model III). SC Leaders' contributions exceed NC Leaders' contributions by about two tokens in all regression models and the difference is always significant at the 1\% level. WC Leaders also contribute about 1 token more than NC Leaders and the difference is highly significant in all models. Differences between the contributions of WC and SC Leaders are significant either at the 5\% or $10 \%$ level depending on the regression model specification. ${ }^{12}$

TABLE 1

Determinants of Leader Contributions

\begin{tabular}{|c|c|c|c|}
\hline & I & II & III \\
\hline 1 if $\mathrm{SC}$ & $\begin{array}{l}2.235^{* * * *} \\
(0.345)\end{array}$ & $\begin{array}{l}2.078^{* * *} \\
(0.364)\end{array}$ & $\begin{array}{l}1.928^{* * * *} \\
(0.384)\end{array}$ \\
\hline 1 if $\mathrm{WC}$ & $\begin{array}{l}1.428^{* * * *} \\
(0.320)\end{array}$ & $\begin{array}{l}1.400^{* * * *} \\
(0.286)\end{array}$ & $\begin{array}{l}1.187^{* * * *} \\
(0.324)\end{array}$ \\
\hline 1 if Male & & $\begin{array}{c}0.287 \\
(0.284)\end{array}$ & $\begin{array}{c}0.401 \\
(0.301)\end{array}$ \\
\hline 1 if Area of Study is Economics & & $\begin{array}{c}-0.841^{* * *} \\
(0.263)\end{array}$ & $\begin{array}{c}-0.876^{* * * *} \\
(0.287)\end{array}$ \\
\hline Willingness to Take Risks & & $\begin{array}{l}-0.010 \\
(0.077)\end{array}$ & $\begin{array}{c}0.001 \\
(0.081)\end{array}$ \\
\hline Machiavellian score & & $\begin{array}{l}-0.021^{* *} \\
(0.010)\end{array}$ & $\begin{array}{l}-0.021^{*} \\
(0.010)\end{array}$ \\
\hline $\begin{array}{l}\text { Number of Known Others in } \\
\text { Session }\end{array}$ & & & $\begin{array}{l}-0.507^{* *} \\
(0.237)\end{array}$ \\
\hline Constant & $\begin{array}{l}0.617^{* * *} \\
(0.180)\end{array}$ & $\begin{array}{l}2.867^{* * * *} \\
(1.323) \\
\end{array}$ & $\begin{array}{l}2.882^{* *} \\
(1.386)\end{array}$ \\
\hline Session dummies & No & No & Yes \\
\hline$N$ & 96 & 96 & 96 \\
\hline$F$-statistic & $F(2,93)=24.55$ & $F(6,89)=16.16$ & $F(12,83)=10.60$ \\
\hline $\begin{array}{l}\text { Prob }>F \\
R^{2}:\end{array}$ & $\begin{array}{l}0.000 \\
0.360\end{array}$ & $\begin{array}{l}0.000 \\
0.447\end{array}$ & $\begin{array}{l}0.000 \\
0.489\end{array}$ \\
\hline
\end{tabular}

OLS regressions. Dependent variable is Leader's contribution. Robust standard errors in parentheses. * $.05 \leq p \leq .10 ; * * .01 \leq p<.05$; *** $p<.01$.

\footnotetext{
${ }^{11}$ Long (1997) (pp. 115-119) discusses the costs and benefits of using a linear regression model (LRM) instead of ordered regression models (ORM) when using ordinal dependent variables and concludes that in general "...the results of the LRM only correspond to those of the ORM if [the cut-points of an ORM] are all about the same distance apart" (p. 119), i.e. if the intervals between adjacent categories of the dependent variable are equal, which is in fact the case for the variable "Leader's contribution". Given their simpler interpretation, OLS estimates are reported hereafter. Any inference based on such estimates can be also derived using ORM estimation.

${ }_{12}$ The p-values from the F-test for equality of coefficients on SC and WC are 0.045 (Model I), 0.069 (Model II), and 0.051 (Model III).
} 
Among the variables controlling for individual characteristics, the dummy identifying subjects studying Economics is highly significant in both the regression models where it is included: Leaders who study Economics appear to contribute significantly less than others. This result is consistent with findings from other laboratory experiments (e.g. Marwell and Ames (1981); Frank, Gilovich and Regan (1993)), although there is an ongoing debate about the reasons for these differences in other-regarding behavior (see, e.g., Frey and Meier (2003)).

Also important is the 'Machiavellianism' of the subject. The coefficient of the Machiavellian score (Christie and Geis (1970)) - a psychometric test where higher scores signal a combination of selfishness and opportunism - is negative and statistically significant in both models: Leaders with high Machiavellian scores tend to contribute less than those who score low in Machiavellianism. This result is consistent with Burks, et al. (2003) who also find that first movers with a high Machiavellian score send less in a trust game where subjects played both roles. ${ }^{13}$

We do not observe a clear gender effect. The regressions show that, after controlling for cooperativeness, males contribute more than females, although the difference is insignificant. Arbak and Villeval (2007) report a similar finding. This result compares also with findings on first-mover's behavior in trust games where men are sometimes found to send larger amounts than women (e.g. Buchan, Croson and Solnick (2008)) but the effect is often not significant (e.g. Croson and Buchan (1999)). ${ }^{14}$

As commitment to a leadership contribution is a risky decision we may expect that Leaders who are more willing to take risks contribute more than those who are less prepared to make risky decisions. Our measurement of subjects' willingness to take risks is instead negatively correlated with leader contributions in Model II, while it enters with a positive coefficient in Model III. In both cases the effect is not statistically significant ( $p=0.896$ in Model II; $p=0.992$ in Model III), suggesting that risk considerations are unimportant for leader decisions in our experiment.

Model III includes session dummies (which are jointly insignificant) and the variable "Number of Known Others in Session" measuring the number of other participants in the session known to the subject. Although the overwhelming majority of participants were strangers to one

\footnotetext{
${ }^{13}$ Across the whole sample scores ranged from 67 to 136. The average score was 98.92 with a standard deviation of 14.11, which is similar to that reported in other experimental studies (e.g. Gunnthorsdottir, et al. (2002); Burks, et al. (2003); Carpenter, et al. (2005); Flues and Gächter (2008)).

${ }^{14}$ See Bohnet (2007) for a discussion of gender effects in trusting behavior. Croson and Gneezy (2009) provide a general review of gender effects in experiments.
} 
another (on average a participant only knew 0.12 other participants), knowing other participants in the session reduces the amount a Leader is willing to contribute.

To get a sense of the importance of assigning given cooperation types to the role of Leader we conducted a simple accounting exercise. For every possible pairing of subjects we calculated total contributions for both possible role assignments. We present the average of these by cooperation type combination in Table 2. For example, on average an SC Leader and NC Follower make a total contribution of 2.85 tokens. For a given Follower type contributions increase with the cooperativeness of the Leader, and for a given Leader type contributions increase with the cooperativeness of the Follower (with one exception: when an NC Leader is paired with a WC Follower contributions are higher than when paired with an SC Follower). Note also that when types differ, contributions are always higher when the more cooperative type occupies the role of Leader. Using the observed distribution of cooperation types we also compute the expected total contribution for each Leader cooperation type. SC Leaders generate more than 4 times as many contributions as NC Leaders.

TABLE 2

Total Contributions by Cooperation Types

\begin{tabular}{c|ccc|c}
\hline \hline \multirow{2}{*}{ Type of Leader } & \multicolumn{3}{|c|}{ Type of Follower } & \\
\hline $\mathrm{NC}$ & 0.63 & 1.24 & 1.17 & 0.92 \\
$\mathrm{WC}$ & 2.05 & 3.66 & 3.70 & 2.87 \\
$\mathrm{SC}$ & 2.85 & 4.40 & 5.32 & 3.89 \\
\hline \hline
\end{tabular}

* The expected total contribution takes into account that a subject cannot be matched with oneself. For instance, for an NC Leader the expected total contribution is calculated as $(0.63 \times 46 / 95)+(1.24 \times 22 / 95)+(1.17 \times 27 / 95)$.

\section{Are Strong Cooperators Better Leaders Because They Are More Optimistic About Followers?}

So far we have shown that cooperation preferences, as measured by conditional contribution decisions, strongly correlate with leader contributions: cooperative Leaders contribute significantly more than non-cooperative Leaders.

However, the large difference in leader contribution decisions between SC, WC and NC subjects observed in our experiment may not necessarily be due to differences in the underlying 
social motivations of these three types. SC, WC and NC subjects may instead hold different expectations about the Follower's behavior, which may in turn drive their contribution decisions. For example, NC subjects may believe that Followers are more likely to behave as a free-riding "NC type", while SC subjects may believe that free-riding behavior is relatively less common and hence may expect a positive return from contributing to the project. Such a systematic bias in beliefs (and in particular the tendency to estimate one's own behavior to be more common than it is estimated by those who engage in alternative behaviors) is called the false consensus effect (Ross, et al. (1977)). ${ }^{15}$

To verify whether a false consensus effect might be driving our results, we start by exploring the relation between subjects' own preferences and their expectations about the cooperation preferences of their opponents, as elicited in the prediction task. As a first step in Figure 3 we draw - both separately for each preference type and aggregated across types - the average conditional contribution decisions that subjects predicted the other person in their group would have made in the role of Follower.

The most remarkable feature of Figure 3 is its similarity with Figure 1, where we depicted subjects' average own contribution decisions by cooperation type. SC and WC contribution decisions are almost identical to their beliefs about others' contribution decisions. NC subjects' predictions of others' contribution decisions differ instead from their own contribution decisions, as these subjects seem to believe that other's contributions increase in the Leader's contribution decisions whereas they always choose to contribute nothing irrespective of the Leader's decision.

\footnotetext{
${ }^{15}$ In the context of cooperation a seminal paper is Kelley and Stahelski (1970). Recent experimental studies finding evidence of a false consensus effect are Selten and Ockenfels (1998), Charness and Grosskopf (2001) and van der Heijden, Nelissen and Potters (2007). Engelmann and Strobel (2000) and Engelmann and Strobel (2007) discuss whether the consensus effect is "truly" false and show that the bias mitigates with the presentation of representative information (see also Offerman, Sonnemans and Schram (1996)).
} 
FIGURE 3

Average Predicted Follower Contribution

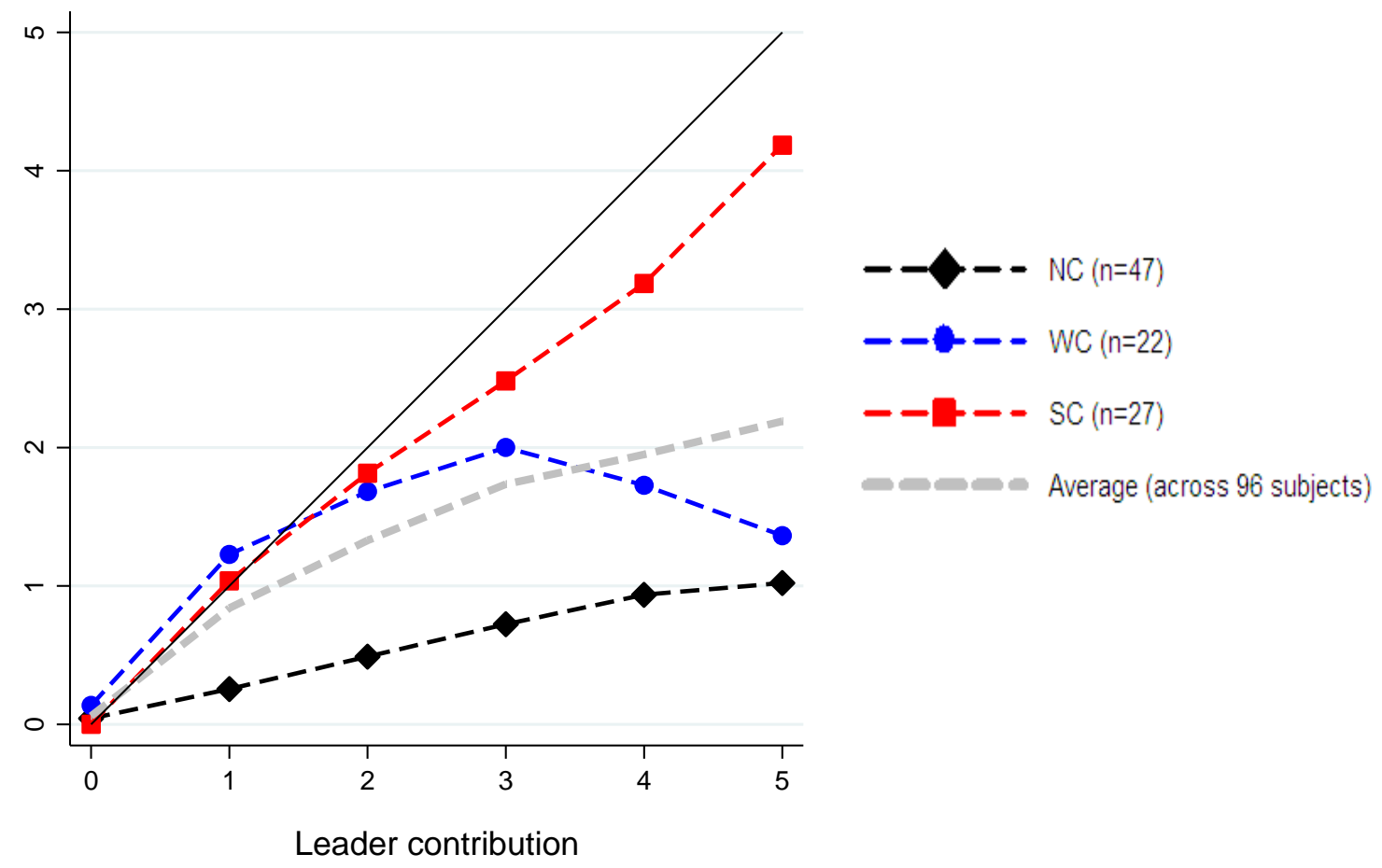

Overall, Figure 3 suggests that different cooperation types hold different beliefs about others' cooperation types. To explore this issue further, we use subjects' predictions about their opponent's conditional contributions to classify subjects according to their predicted Follower type. Our classification method parallels the one we used to classify cooperation types. If a subject predicts that the opponent will contribute nothing to the project irrespective of the leader contribution we classify that subject as having a predicted Non-Cooperator Follower. ${ }^{16}$ If a subject predicts that the Follower will contribute something in response to some Leader contribution, we classify the subject as having a predicted Other, Weak Cooperator, or Strong Cooperator Follower depending on whether a risk-neutral selfish Leader's optimal choice would

\footnotetext{
${ }^{16}$ One might worry that subjects may report biased beliefs in the Prediction Task in order to hedge against risk. For example, a Leader who contributes five tokens will receive a low payoff if the Follower contributes zero. Even if the Leader expects the Follower to reciprocate he may predict the Follower will contribute zero in order to insure against the worst possible case. If this were indeed the case, Leaders who contribute more would report more pessimistic beliefs about the Follower's cooperativeness. In fact, Figure 3 suggests the opposite: more cooperative Leaders predict higher contribution by the Follower. More generally, we note that there is very limited evidence of hedging in sequential prisoner's dilemma experiments when first-movers predict second-mover's choices (see, e.g., Blanco, et al. (2008)).
} 
be to contribute zero, some, or all of her endowment to the project. ${ }^{17}$. Figure 4 shows separately for each preference type - the proportion of Leaders who predict an NC, WC, SC or Other Follower.

FIGURE 4

Proportions of Predicted Follower Type by each Type of Leader

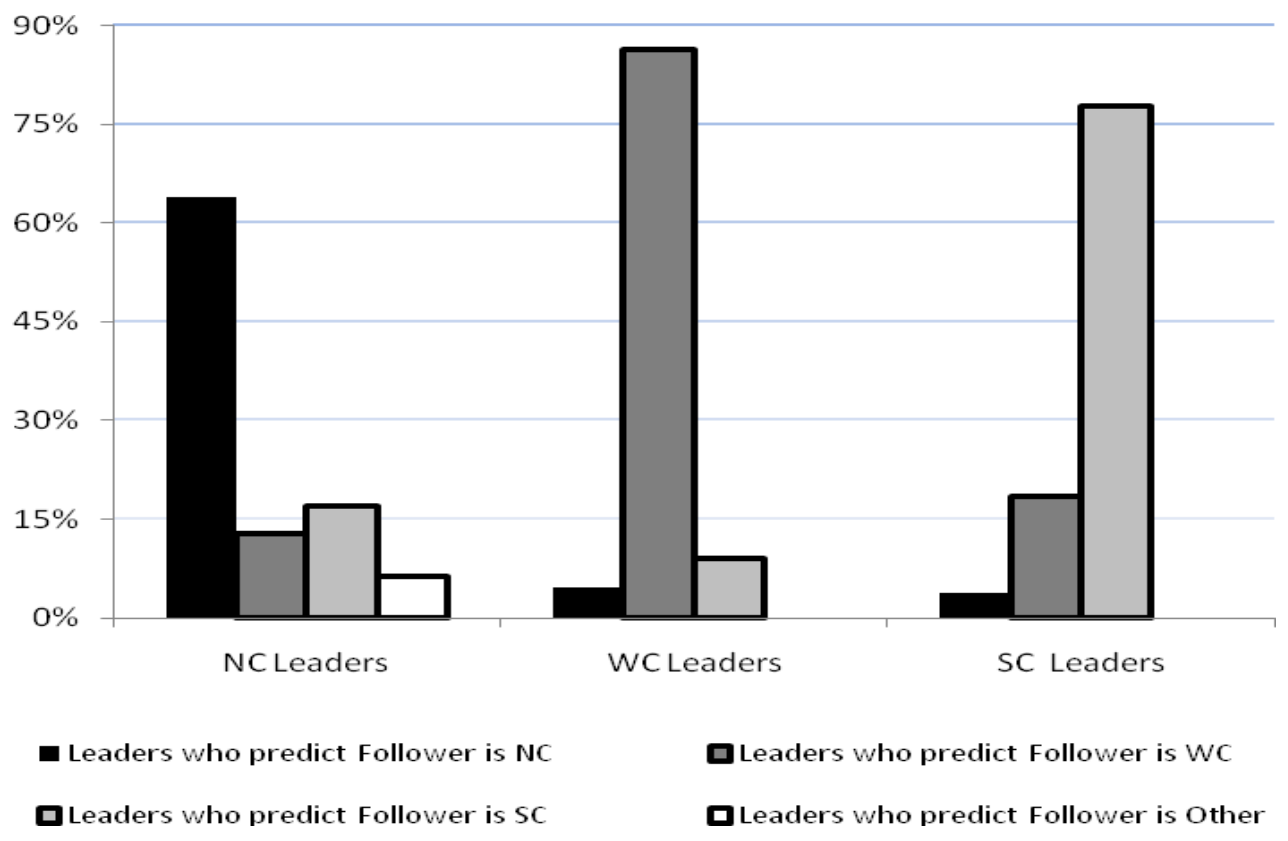

Clearly, subjects' predictions about others' preferences are strongly biased towards their own preference type: more than $60 \%$ of NC Leaders predict that they are matched with a NC Follower, more than $80 \%$ of WC Leaders predict they are matched with a WC Follower, whereas almost $80 \%$ of SC Leaders predict that the person they are matched with is also a SC type. We can strongly reject the hypothesis that the distribution of predicted cooperation types is the same across the three Leader types: $\chi^{2}(6 d . f)=81.11,. p<0.001$. Pair-wise Fisher exact tests

\footnotetext{
${ }^{17}$ We thought it natural to convert the vector of predictions into a type using the same method as that used to convert the vector of Follower choices into a cooperation type. However, the predicted Follower type labels should interpreted with caution. The optimal contribution of a risk neutral selfish Leader depends on the expected responses to the six possible leader contributions and, as noted previously, our belief elicitation procedure gives subjects an incentive to reveal the most likely response to each leader contribution. Thus a risk-neutral selfish Leader may not necessarily find it optimal to contribute five tokens against a predicted SC Follower type.
} 
performed separately for each preference type are all significant at the $1 \%$ level. Thus, subjects' predictions about others' preference types are consistent with a false consensus effect. ${ }^{18}$

Our next step is to explore whether such a false consensus effect is actually driving our results about differences in leader contributions across preference types. It may be that differences in cooperation preferences are not the reason why SC subjects contribute more than NC subjects in the role of leader. Instead, SC subjects may choose to make larger leader contributions than NC subjects because they are more optimistic that Followers will respond with positive contributions. If this is in fact the case, we would then expect that, for a given belief about the opponent's type, leader contributions would not be significantly different across Leader's preference types.

To explore this issue we augment our regression analysis of Leaders' contributions developed in Models I to III and reported in Table 1 above with the variable "Degree of Optimism". This variable measures the Leader's best-response to his or her own predictions about the opponent's conditional contribution decisions. The higher the Leader's best-response to his or her own beliefs, the more optimistic he or she is about the cooperativeness of their Follower: the most optimistic Leaders are those whose best-response is to contribute 5 tokens to the joint project because, as explained above, these Leaders predict that the Follower is a Strong Cooperator. The least optimistic Leaders are those whose best-response is to contribute nothing: these subjects predict that they are matched either with a Non-Cooperator or with a Follower that belongs to the category Other. Leaders whose best-response range from 1 to 4 predict that they are matched with a Weak Cooperator. ${ }^{19}$

The results of the regressions are shown in Table $3 .^{20}$ The variable "Degree of Optimism" is significant and positive in all three models: consistent with a belief-based explanation of differing leader contributions across types Leaders who are more optimistic about the

\footnotetext{
${ }^{18}$ One may argue that such a strong bias towards the own preference type may be due to the fact that subjects do not report their beliefs truthfully but rather in a way that satisfies the need to see oneself behaving "as others do" and hence behaving appropriately. In fact, one potential explanation for the false consensus effect is based on such a "motivational" mechanism. However, if this is the case, one would also expect the bias to disappear or to be mitigated in the presence of financial incentives and to be stronger for answers to questions about socially desirable/undesirable activities. However, the false consensus effect has also been reproduced in the presence of monetary incentives, as in the present experiment. Moreover, a false consensus effect has been found also in studies employing morally neutral questions (see, e.g., Engelmann and Strobel (2000); Engelmann and Strobel (2007)).

${ }^{19}$ Again, the caveat noted in footnote 17 applies.

${ }^{20}$ Because Leaders' type and degree of optimism are correlated it may be difficult to identify the contribution of each factor to leader contributions if there is a co-linearity problem. However, checks for multicollinearity (based on variance inflation factor values) suggest that this is not the case for the Models reported in Table 3.
} 
cooperativeness of their Follower make higher contributions. Nevertheless, for a given degree of optimism, WC Leaders still contribute about one token more than NC Leaders, and SC Leaders contribute about $1 \frac{1}{1} 2$ tokens more than NC Leaders (both coefficients are significantly different from zero at the $1 \%$ or $5 \%$ level). Hence, Leaders with the same degree of optimism do make different contributions depending on their preference type.

Our controls for individual characteristics and session effects substantially reproduce the same pattern of results observed in the regressions reported in Table 1: Leaders studying Economics contribute significantly less than others, as do Leaders with high Machiavellian scores, as do Leaders who know more other participants in the session. Session dummies, included in Model III, are jointly insignificant, as is the dummy controlling for gender and our measure of subjects' risk attitudes.

TABLE 3

Leader Contribution and Degree of Optimism

\begin{tabular}{|c|c|c|c|}
\hline & I & II & III \\
\hline 1 if $\mathrm{SC}$ & $\begin{array}{l}1.712^{* * * *} \\
(0.497)\end{array}$ & $\begin{array}{l}1.503^{* * * *} \\
(0.462)\end{array}$ & $\begin{array}{l}1.427^{* * * *} \\
(0.524)\end{array}$ \\
\hline 1 if $\mathrm{WC}$ & $\begin{array}{l}1.228^{* * * *} \\
(0.344)\end{array}$ & $\begin{array}{l}1.193^{* * * *} \\
(0.295)\end{array}$ & $\begin{array}{l}0.966^{* * *} \\
(0.375)\end{array}$ \\
\hline Degree of Optimism & $\begin{array}{l}0.167^{*} \\
(0.097)\end{array}$ & $\begin{array}{l}0.175^{* * *} \\
(0.084)\end{array}$ & $\begin{array}{l}0.159^{*} \\
(0.095)\end{array}$ \\
\hline 1 if Male & & $\begin{array}{c}0.265 \\
(0.266)\end{array}$ & $\begin{array}{c}0.349 \\
(0.280)\end{array}$ \\
\hline 1 if Area of Study is Economics & & $\begin{array}{c}-0.913^{* * * *} \\
(0.265)\end{array}$ & $\begin{array}{c}-0.925^{* * *} \\
(0.286)\end{array}$ \\
\hline Willingness to take risks & & $\begin{array}{l}-0.023 \\
(0.078)\end{array}$ & $\begin{array}{l}-0.011 \\
(0.084)\end{array}$ \\
\hline Machiavellian score & & $\begin{array}{l}-0.019^{*} \\
(0.010)\end{array}$ & $\begin{array}{l}-0.019^{*} \\
(0.011)\end{array}$ \\
\hline $\begin{array}{l}\text { Number of Known Others in } \\
\text { Session }\end{array}$ & & & $\begin{array}{l}-0.417^{*} \\
(0.224)\end{array}$ \\
\hline Constant & $\begin{array}{l}0.414^{* * *} \\
(0.175)\end{array}$ & $\begin{array}{l}2.594^{*} \\
(1.345)\end{array}$ & $\begin{array}{l}2.523^{*} \\
(1.465)\end{array}$ \\
\hline Session dummies & $\begin{array}{l}\text { No } \\
96\end{array}$ & $\begin{array}{l}\text { No } \\
96\end{array}$ & $\begin{array}{l}\text { Yes } \\
96\end{array}$ \\
\hline $\begin{array}{l}N . \\
\text { F-statistic }\end{array}$ & $\begin{array}{c}96 \\
F(3,92)=20.16\end{array}$ & $\begin{array}{c}96 \\
F(7,88)=14.30\end{array}$ & $\begin{array}{c}96 \\
F(13,82)=10.54\end{array}$ \\
\hline Prob $>F$ & 0.000 & 0.000 & 0.000 \\
\hline$R^{2}$ & 0.390 & 0.479 & 0.510 \\
\hline
\end{tabular}

OLS regressions. Dependent variable is Leader's contribution. Robust standard errors in parentheses. ${ }^{*} .05 \leq p \leq .10 ; * * .01 \leq p<.05 ; * * * *<.01$. 
Overall, these results show that Leaders' expectations about their opponent's preference type are systematically biased towards their own preference type (i.e. they are influenced by a false consensus effect). However, the large differences in leader contribution decisions between SC, WC and NC subjects that we observed in our experiment cannot be entirely explained in terms of systematic differences in expectations about others' cooperation preferences, because for a given belief about the Follower's cooperativeness, leader contributions are still significantly different across Leader's preference types.

\section{DISCUSSION \& CONCLUSIONS}

We examine how cooperativeness and beliefs about the cooperativeness of others affect leadership contributions in a simple leader-follower game. The game uses the same type of earnings functions used in experiments examining voluntary contributions to a public good. Thus, a Follower's contribution increases group earnings at the expense of the Follower's narrow personal interests. Our experiment allows Leaders to attempt to induce such group-oriented behavior through "leading-by-example": by contributing Leaders might, if the Follower is sufficiently conditionally cooperative, induce the Follower to contribute as well. Our focus is on the extent to which the Leader's willingness to lead-by-example depends on her own cooperation preferences, her beliefs about the cooperation preferences of her Follower, and other personal characteristics.

As in previous experiments we find that many Followers are conditionally cooperative and are willing to reciprocate the Leader's contribution. About half of our subjects exhibit a degree of conditional cooperativeness such that it pays for a self-interested Leader to contribute something, and about half of these cooperators are classified as "Strong Cooperators", as they are conditionally cooperative to the extent that a self-interested Leader should contribute her entire endowment. These cooperation preferences are strongly correlated with (unconditional) Leader decisions. For example Strong Cooperator Leaders contributed around 57\% of their endowments, significantly more than Non-Cooperator Leaders who contributed only $12 \%$ of their endowments. Part of this effect can be explained by subjects' personal characteristics. Economists contribute less as Leaders, as do those who are more 'Machiavellian'. However, even after controlling for 
these personal characteristics, Strong Cooperator Leaders contribute $40 \%$ more of their endowments than Non-Cooperator Leaders.

Our finding that Strong Cooperators make higher Leader contributions than Non-Cooperators is in line with recent studies from trust and sequential social dilemma games where subjects play both roles. For example Altmann, et al. (2008) and Chaudhuri and Gangadharan (2007) both find that trustees who reciprocate more are more trusting in trust games. We see two main differences between trust games and our leader-follower game. First, our focus on leading-by-example has guided our choice of a game where the leader and follower have identical choice sets and earnings functions, and so the leader's decision can be easily viewed as an "example" to the follower. In the trust game there is an asymmetry between roles that goes beyond the sequential structuring of choices, and this asymmetry makes it less clear that the trustor can "lead by example". Second, in our game the follower's decision affects group earnings, whereas in a trust game the secondmover's decision is a pure transfer, only affecting the distribution of group earnings.

Altmann, et al. (2008) speculate that a false consensus effect, whereby selfish subjects believe others are selfish and reciprocal subjects believe others are reciprocal, could explain why reciprocal trustees trust more in their experiment. The same effect may also explain why Strong Cooperators make higher Leader contributions in our experiment - they may be more optimistic about the cooperativeness of Followers. Similarly, this could explain the positive correlation between decisions as first-mover and second-mover reported in sequential social dilemma game experiments where subjects play both roles (see, e.g., Fischbacher, et al. (2001); Blanco, et al. (2008); Bruttel and Eisenkopf (2009)). Differently from these studies, our design allows us to control for differences in beliefs, and we do indeed find a strong correlation between own cooperation preferences and beliefs about the cooperation preferences of others: Strong Cooperators are more optimistic about the chances of being paired with another Strong Cooperator. However, even after controlling for optimism, Strong Cooperators contribute about $30 \%$ more of their endowment than Non-Cooperator Leaders. Thus, differing degrees of optimism can only explain part of the difference between the Leader contributions of Non-Cooperators and Strong Cooperators and most of the difference reflects their differing social motivations.

Our findings are comparable with those reported in a recent experiment by Blanco, et al. (2009). Their extensive design uses several treatments to examine the relationship between cooperativeness and beliefs in a sequential prisoner's dilemma game experiment where subjects 
play both roles. In their Baseline treatment they do not elicit beliefs about second-movers' cooperativeness, and find, like the studies cited above, that a majority of subjects make the same choice as a first-mover and as a second-mover. The correlation between first and second mover decisions persists in a second treatment where, as in our experiment, they elicit subjects' beliefs about second-movers' cooperativeness. They find that beliefs about second movers' cooperativeness are positively related to subjects' own cooperativeness, which is consistent with a consensus effect. In a third treatment, Blanco, et al. (2009) provide subjects with feedback about the true distribution of second-movers' cooperativeness before eliciting their first-mover decisions. They find that the correlation between first-mover and second-mover decisions persists even when accurate feedback about second-movers' cooperativeness is provided, suggesting that a consensus effect can only provide a partial explanation for the positive correlation between firstmover and second-mover decisions observed in their experiments. ${ }^{21}$ Our findings are also consistent with those of Vyrastekova and Garikipati (2005): using a trust game, they correlate trustor decisions with their beliefs about the trustee's decision and with their distributional preferences as measured using the "Decomposed Game technique", an instrument developed by sociologists and social psychologists to assess individual value orientations (see, e.g., Liebrand, et al. (1986)). They find a strong relation between distributional preferences and trustor decisions even after controlling for beliefs. They also find that beliefs are strongly correlated with distributional preferences.

We only address a narrow aspect of leadership: leading-by-example. Nevertheless our results are suggestive that effective leadership will depend on the leader's cooperative preferences and beliefs. To the extent that a large part of the variation in Leader contributions can be explained by cooperation preferences, even after controlling for optimism, this suggests that groups may perform better when led by individuals who are willing to sacrifice personal benefit for the greater good. Further, since beliefs are highly correlated with cooperation preferences, such individuals are more likely to have optimistic views about Followers that will reinforce their propensity to contribute. While non-cooperative Leaders could, in principle, do

\footnotetext{
${ }^{21}$ Note that their subjects are classified as cooperative or not according to whether, as second-mover, they cooperate or defect in response to cooperate. Our second movers fill in a contribution schedule indicating how may tokens they contribute (up to 5) for each possible contribution decision by the first mover (again, a number from 0 to 5). We measure a subject's degree of cooperativeness based on the slope of this contribution schedule.
} 
anything that an optimistic cooperator does, their cooperation preferences and expectations about others may make them less likely to provide effective leadership.

A natural question that follows from our findings and that may be particularly relevant in settings that involve repeated interactions is whether it is more beneficial for the group that the most cooperative individuals set an example by committing to an initial contribution, or whether it can be better to have other, less cooperative individuals move first and let strong cooperators observe their contributions and discipline them. Rivas and Sutter (2008) report on an experiment where they let leaders move after other subjects have made a contribution and find that this does not affect cooperation rates in a simple public good setting. However, they do not selectively choose the most cooperative types as leaders in their experiment. Moreover, leaders in their study can only discipline first-movers through their own contribution decisions. An interesting development, which we leave for further investigation, would be to assess how cooperativeness is affected when second-movers are given some form of sanctioning or rewarding power such that they can effectively discipline early contributors' behavior. 


\section{References}

Altmann, S., T. Dohmen, and M. Wibral. "Do the Reciprocal Trust Less?" Economics Letters, 99, 2008, 454-457.

Arbak, E., and M.-C. Villeval. "Endogenous Leadership: Selection and Influence." IZA Discussion Paper No. 2732, Institute for the Future of Labor, Bonn, 2007.

Blanco, M., D. Engelmann, A. K. Koch, and H.-T. Normann. "Belief Elicitation in Experiments: Is There a Hedging Problem?" IZA Discussion Paper No. 3517, Institute for the Future of Labor, Bonn, 2008.

—. "Preferences and Beliefs in the Sequential Prisoner's Dilemma: A within-Subjects Analysis." mimeo, University of Aarhus, 2009.

Blanco, M., D. Engelmann, and H.-T. Normann. "A within-Subjects Analysis of OtherRegarding Preferences." Working paper, Royal Holloway, University of London, 2008.

Bohnet, I. "Why Women and Men Trust Others." In Economics and Psychology, ed. B. S. Frey, \& A. Stutzer. Cambridge, MA: The MIT Press, 2007.

Bruttel, L., and G. Eisenkopf. "Incentive Compatible Contracts?" Research Paper No. 43, Thurgau Institute of Economics and Department of Economics at the University of Konstanz, 2009.

Buchan, N. R., R. T. A. Croson, and S. Solnick. "Trust and Gender: An Examination of Behavior and Beliefs in the Investment Game." Journal of Economic Behavior \& Organization, 68, 2008, 466-476.

Burks, S. V., J. P. Carpenter, and E. Verhoogen. "Playing Both Roles in the Trust Game." Journal of Economic Behavior \& Organization, 51, 2003, 195-216.

Carpenter, J., E. Verhoogen, and S. V. Burks. "The Effect of Stakes in Distribution Experiments." Economic Letters, 86, 2005, 393-398.

Carpenter, J. P., S. Burks, and E. Verhoogen. "Comparing Students to Workers: The Effect of Stakes, Social Framing, and Demographics on Bargaining Outcomes." In Field Experiments in Economics. Research in Experimental Economics, ed. J. P. Carpenter, G. Harrison, \& J. List. Amsterdam: Elsevier JAI, 2005.

Charness, G., and B. Grosskopf. "Relative Payoffs and Happiness: An Experimental Study." Journal of Economic Behavior \& Organization, 45, 2001, 301-328.

Chaudhuri, A., and L. Gangadharan. "An Experimental Analysis of Trust and Trustworthiness." Southern Economic Journal, 73, 2007, 959-985.

Christie, R., and F. L. Geis. Studies in Machiavellianism. New York and London: Academic Press, 1970.

Clark, K., and M. Sefton. "The Sequential Prisoner's Dilemma: Evidence on Reciprocation." Economic Journal, 111, 2001, 51-68.

Croson, R. "Theories of Commitment, Altruism and Reciprocity: Evidence from Linear Public Goods Games." Economic Inquiry, 45, 2007, 199-216.

Croson, R., and N. Buchan. "Gender and Culture: International Experimental Evidence from Trust Games." American Economic Review, 89, 1999, 386-391.

Croson, R., and U. Gneezy. "Gender Differences in Preferences." Journal of Economic Literature, 47, 2009, 1-27.

Dohmen, T., A. Falk, D. Huffman, U. Sunde, J. Schupp, and G. Wagner. "Individual Risk Attitudes: Measurement, Determinants and Behavioral Consequences." Journal of the European Economic Association, forthcoming. 
Drucker, P. F. The Daily Drucker: 366 Days of Insight and Motivation for Getting the Right Things Done. New York: Collins Business, 2004.

Engelmann, D., and M. Strobel. "The False Consensus Effect Disappears If Representative Information and Monetary Incentives Are Given." Experimental Economics, 3, 2000, 241-260.

-. "Deconstruction and Reconstruction of an Anomaly." Working Paper, Royal Holloway, available at http://personal.rhul.ac.uk/unte/247/research.html, 2007.

Fischbacher, U. "Z-Tree: Zurich Toolbox for Readymade Economic Experiments." Experimental Economics, 10, 2007, 171-178.

Fischbacher, U., S. Gächter, and E. Fehr. "Are People Conditionally Cooperative? Evidence from a Public Goods Experiment." Economics Letters, 71, 2001, 397-404.

Flues, F., and S. Gächter. "Machiavellian Cooperators and Punishers." mimeo, University of Nottingham, 2008.

Frank, R. H., T. Gilovich, and D. T. Regan. "Does Studying Economics Inhibit Cooperation?" Journal of Economic Perspectives, 7, 1993, 159-171.

Frey, B. S., and S. Meier. "Are Political Economists Selfish and Indoctrinated? Evidence from a Natural Experiment." Economic Inquiry, 41, 2003, 448-462.

—. "Social Comparisons and Pro-Social Behavior. Testing 'Conditional Cooperation' in a Field Experiment." American Economic Review, 94, 2004, 1717-1722.

Gächter, S., and E. Renner. "Leading by Example in the Presence of Free Rider Incentives." paper presented at a Conference on Leadership, March 2003, Lyon, 2003.

-. "The Role of Leadership and Beliefs in the Voluntary Provision of Public Goods." mimeo, University of Nottingham, 2007.

Glöckner, A., B. Irlenbusch, S. Kube, A. Nicklisch, and H.-T. Normann. "Leading with(out) Sacrifice? A Public-Goods Experiment with a Super-Additive Player." Economic Inquiry, forthcoming.

Greiner, B. "An Online Recruitment System for Economic Experiments." In Forschung Und Wissenschaftliches Rechnen Gwdg Bericht 63, ed. K. Kremer, \& V. Macho. Göttingen: Gesellschaft für Wissenschaftliche Datenverarbeitung, 2004.

Güth, W., M. V. Levati, M. Sutter, and E. Van Der Heijden. "Leading by Example with and without Exclusion Power in Voluntary Contribution Experiments." Journal of Public Economics, 91, 2007, 1023-1042.

Gunnthorsdottir, A., K. Mccabe, and V. Smith. "Using the Machiavellianism Instrument to Predict Trustworthiness in a Bargaining Game." Journal of Economic Psychology, 23, 2002, 49-66.

Kelley, H., and A. Stahelski. "Social Interaction Basis of Cooperators' and Competitors' Beliefs About Others." Journal of Personality and Social Psychology, 16, 1970, 190-219.

Keser, C., and F. Van Winden. "Conditional Cooperation and Voluntary Contributions to Public Goods." Scandinavian Journal of Economics, 102, 2000, 23-39.

Kumru, C., and L. Vesterlund. "The Effect of Status on Voluntary Contribution." Working Paper, University of Pittsburgh, available at http://www.pitt.edu/ vester/research.html, 2008.

Levati, M. V., M. Sutter, and E. Van Der Heijden. "Leading by Example in a Public Goods Experiment with Heterogeneity and Incomplete Information." Journal of Conflict Resolution, 51, 2007, 793-818. 
Liebrand, W. B. G., R. W. T. L. Jansen, V. M. Rijken, and C. J. M. Suhre. "Might over Morality: Social Values and the Perception of Other Players in Experimental Games." Journal of Experimental Social Psychology, 22, 1986, 203-215.

Long, S. J. Regression Models for Categorical and Limited Dependent Variables. Thousand Oaks, CA: SAGE Publications, 1997.

Marwell, G., and R. E. Ames. "Economists Free Ride, Does Anyone Else? Experiments on the Provision of Public Goods, Iv." Journal of Public Economics, 15, 1981, 295-310.

Meyer, H.-D. "Norms and Self-Interest in Ultimatum Bargaining: The Prince's Prudence." Journal of Economic Psychology, 13, 1992, 215-232.

Moxnes, E., and E. Van Der Heijden. "The Effect of Leadership in a Public Bad Experiment." Journal of Conflict Resolution, 47, 2003, 776-795.

Offerman, T., J. Sonnemans, and A. Schram. "Value Orientations, Expectations and Voluntary Contributions in Public Goods." Economic Journal, 106, 1996, 817-845.

Pogrebna, G., D. Krantz, C. Schade, and C. Keser. "Leadership by Example and by Pre-Game Communication in Social Dilemma Situations." unpublished paper available at: http://ssrn.com/abstract=1247262, 2009.

Potters, J., M. Sefton, and L. Vesterlund. "Leading-by-Example and Signaling in Voluntary Contribution Games: An Experimental Study." Economic Theory, 33, 2007, 169-182.

Rivas, M. F., and M. Sutter. "The Dos and Don'ts of Leadership in Sequential Public Goods Experiments." University of Innsbruck, Working Papers in Economics and Statistics, 2008-25, 2008.

Ross, L., D. Greene, and P. House. "The "False Consensus Effect": An Egocentric Bias in Social Perception and Attribution Processes." Journal of Experimental Social Psychology, 13, 1977, 279-301.

Selten, R. "Die Strategiemethode Zur Erforschung Des Eingeschränkt Rationalen Verhaltens Im Rahmen Eines Oligopolexperimentes." In Beiträge Zur Experimentellen Wirtschaftsforschung, ed. H. Sauermann. Tübingen: J.C.B. Mohr (Paul Siebeck), 1967.

Selten, R., and A. Ockenfels. "An Experimental Solidarity Game." Journal of Economic Behavior \& Organization, 34, 1998, 517-539.

Spitzer, M., U. Fischbacher, B. Herrnberger, G. Gron, and E. Fehr. "The Neural Signature of Social Norm Compliance." Neuron, 56, 2007, 185-196.

Van Der Heijden, E., J. Nelissen, and J. Potters. "Opinions on the Tax Deductibility of Mortgages and the Consensus Effect." De Economist, 155, 2007, 141-159.

Van Vugt, M., and D. De Cremer. "Leadership and Cooperation in Groups: Integrating the Social Dilemma and Social Identity Perspectives." European Review of Social Psychology, 13, 2002, 155-184.

Vyrastekova, J., and S. Garikipati. "Beliefs and Trust: An Experiment." CentER Discussion Paper No. 2005-88, University of Tilburg, 2005.

Yukl, G. A. Leadership in Organizations. Englewood Cliffs, NJ: Prentice Hall, 1989. 
Appendix: Experimental Instructions

\section{Instructions}

\section{General}

Welcome! You are about to take part in a decision-making experiment. It is important that you do not talk to any of the other participants until the experiment is over. If you have a question at any time, raise your hand and a monitor will come to your desk to answer it.

In this experiment you will be randomly paired with another person in this room. The amount you earn will depend on your decisions and the decisions of the person you are paired with. You will not learn the identity of the person you are paired with, neither during nor after today's session. You will be paid in private and in cash at the end of the experiment.

\section{The Basic Decision Situation}

The basic decision situation is simple. In each pair one person is designated as the "FIRST MOVER" and the other as the "SECOND MOVER". Each person is endowed with five tokens. The FIRST MOVER first decides how many of his or her tokens to contribute to a joint project. The SECOND MOVER is then informed of the FIRST MOVER's decision. The SECOND MOVER then decides how many of his or her tokens to contribute to the project.

Earnings depend on the decisions as follows.

For each token contributed to the project, the FIRST MOVER and the SECOND MOVER get $£ 1$ each.

For each token a person does not contribute to the project, that person gets $£ 1.50$.

So that everyone understands how choices translate into earnings we will give an example and a test. (The allocations of tokens used for the example and test are simply for illustrative purposes. In the experiment the allocations will depend on the actual choices of the participants.)

Example: Suppose the FIRST MOVER contributes 2 tokens to the project, and the SECOND MOVER contributes 4 tokens to the project. Thus in total 6 tokens are contributed to the project.

The FIRST MOVER will earn $6 \times £ 1=£ 6$ from the project and $3 \times £ 1.50=£ 4.50$ from the 3 tokens he or she has not contributed to the project. Thus, the FIRST MOVER's total earnings will be $£ 6+£ 4.50=$ $£ 10.50$.

The SECOND MOVER will earn $6 \times £ 1=£ 6$ from the project and $1 \times £ 1.50=£ 1.50$ from the 1 token he or she has not contributed to the project. Thus, the SECOND MOVER's total earnings will be $£ 6+£ 1.50$ $=£ 7.50$. 
Test: Before we continue with the instructions we want to make sure that everyone understands how their earnings are determined. Please answer the questions below. After a few minutes a monitor will check your answers. When everyone has answered the questions correctly we will continue with the instructions. Raise your hand if you have a question.

1. Suppose the FIRST MOVER contributes 5 tokens to the project, and the SECOND MOVER contributes 5 tokens to the project. Thus, in total 10 tokens are contributed to the project.

* How much will the FIRST MOVER earn from the project?

* How much will the FIRST MOVER earn from the tokens he or she does not contribute to the project?

* How much will the FIRST MOVER earn in total?

* How much will the SECOND MOVER earn from the project?

* How much will the SECOND MOVER earn from the tokens he or she does not contribute to the project?

* How much will the SECOND MOVER earn in total?

2. Suppose the FIRST MOVER contributes 0 tokens to the project, and the SECOND MOVER contributes 0 tokens to the project. Thus, in total 0 tokens are contributed to the project.

* How much will the FIRST MOVER earn from the project?

* How much will the FIRST MOVER earn from the tokens he or she does not contribute to the project?

* How much will the FIRST MOVER earn in total?

* How much will the SECOND MOVER earn from the project?

* How much will the SECOND MOVER earn from the tokens he or she does not contribute to the project?

* How much will the SECOND MOVER earn in total?

3. Suppose the FIRST MOVER contributes 1 token to the project, and the SECOND MOVER contributes 4 tokens to the project. Thus, in total 5 tokens are contributed to the project.

* How much will the FIRST MOVER earn from the project?

* How much will the FIRST MOVER earn from the tokens he or she does not contribute to the project?

* How much will the FIRST MOVER earn in total?

* How much will the SECOND MOVER earn from the project?

* How much will the SECOND MOVER earn from the tokens he or she does not contribute to the project?

* How much will the SECOND MOVER earn in total? 


\section{How You Make Decisions}

You will make decisions on the computer by completing a screen. The attached sheet shows what the screen will look like. We want to know what you would do in the role of the FIRST MOVER and what you would do in the role of the SECOND MOVER. Thus you will be prompted to make decisions in both roles. Only after you have made your decisions will the computer inform you of your actual role, "FIRST MOVER" or "SECOND MOVER", and this will determine your relevant decisions for calculating earnings. The computer will select roles randomly: there is a 50\% chance you will be the FIRST MOVER and the person you are paired with will be the SECOND MOVER, and a 50\% chance you will be the SECOND MOVER and the person you are paired with will be the FIRST MOVER.

DECISION TASK 1: In the first blank field you must enter your contribution decision in the role of the FIRST MOVER. You simply indicate how many tokens to contribute to the project. You can enter any whole number from 0 to 5 inclusive.

DECISION TASK 2: The next set of blank fields is for your contribution decision in the role of the SECOND MOVER. We want to know what you as SECOND MOVER would do for any contribution that the FIRST MOVER might make. That is, we want to know:

- what you would do if the FIRST MOVER contributed zero tokens to the project,

- what you would do if the FIRST MOVER contributed one token,

- what you would do if the FIRST MOVER contributed two tokens, etc.

Thus the SECOND MOVER will be prompted to make a decision for every possible contribution by the FIRST MOVER. The relevant decision will be determined by the FIRST MOVER's actual contribution. If the FIRST MOVER contributed zero tokens to the project, the SECOND MOVER's contribution will be the number he or she types in the first box. If the FIRST MOVER contributed one token to the project, the SECOND MOVER's contribution will be the number he or she types in the second box, and so on. In each box you can enter any whole number from 0 to 5 inclusive.

The screen also has a final set of blank fields for a PREDICTION TASK. Here you must enter a prediction about what the other person enters for DECISION TASK 2.

Once you have completed the decision and prediction tasks you should click on the "Submit" button. You will then be prompted to either change or confirm your decisions and predictions. At this point, if you want to you will be able to go back and change your entries. Once you confirm your decisions and predictions you cannot change them. When everyone in the room has submitted and confirmed their decisions and predictions earnings will be calculated. 


\section{How Your Cash Earnings Are Determined}

First you will be informed of whether you are the FIRST MOVER or the SECOND MOVER. The computer then determines contributions from decisions as follows.

If you are the FIRST MOVER your contribution is determined by what you entered in DECISION TASK 1. The other person's contribution is determined by what they entered in DECISION TASK 2 in the box corresponding to your contribution.

If you are the SECOND MOVER the other person's contribution is determined by what they entered in DECISION TASK 1. Your contribution is determined by what you entered in DECISION TASK 2 in the box corresponding to the other person's contribution.

From these contributions earnings are calculated. For each token you do not contribute to the project you get $£ 1.50$ and for each token contributed to the project the FIRST MOVER and the SECOND MOVER get $£ 1$ each.

\section{Bonus Earnings}

In addition, you can earn money from correctly predicting what the other person enters for DECISION TASK 2. Your predictions in the PREDICTION TASK will be compared with what the person you are matched with actually did in DECISION TASK 2. For each correct prediction you will receive 50p.

\section{Beginning the Experiment}

Note: in this experiment you will complete ONLY ONE screen. After you submit your entries you will be prompted to confirm them. At this point, if you want to you will be able to change your entries. Once you confirm your entries you cannot change them, and these will be used for determining earnings. If you have a question at any time please raise your hand and a monitor will come to your desk to answer it. Now, please look at your computer screen and begin making your decisions and predictions. 


\section{DECISION TASK 1 - SUPpose you are the FIRST MOVER:}

Choose how many tokens YOU want to contribute to the project.

How many tokens do YOU want to contribute to the project?

\section{DECISION TASK 2 - Suppose you are the SECOND MOVER:}

Choose how many tokens YOU want to contribute to the project for each possible contribution decision of the FIRST MOVER

The FIRST MOVER contribution to the project:

YOUR contribution to the project:

\begin{tabular}{|l|l|l|l|l|l|l|}
\hline 0 & 1 & 2 & 3 & 4 & 5 \\
\hline & & & & & & \\
\hline
\end{tabular}

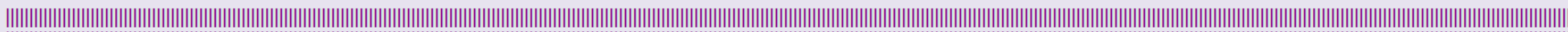

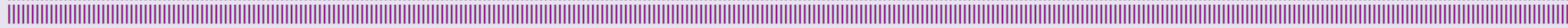

\section{PREDICTION TASK:}

Predict how the person you are matched with has filled out DECISION TASK 2

The FIRST MOVER contribution to the project:

YOUR prediction of the OTHER PERSON's most likely contribution to

the project:

\begin{tabular}{|l|l|l|l|l|l|l|}
0 & 1 & 2 & 3 & 4 & 5 \\
\hline & & & & & \\
\hline
\end{tabular}

In each box you can enter any whole number from 0 to 5 inclusive.

After you have completed the three tasks, please confirm your entries by clicking on the SUBMIT button. 